\title{
EGFRvIII Positive
}

National Cancer Institute

\section{Source}

National Cancer Institute. EGFRVIII Positive. NCI Thesaurus. Code C150485.

An indication that expression of EGFRvIII has been detected in a sample. 